\title{
A IMPORTÂNCIA DA FALA NO PROCESSO TERAPÊUTICO NA ABORDAGEM FENOMENOLÓGICA DASEINSANALÍTICA
}

\author{
LA IMPORTANCIA DEL HABLA EN EL PROCESO TERAPÉUTICO EN EL \\ ENFOQUE FENOMENOLÓGICO DASEINSANALÍTICO
}

\author{
THE IMPORTANCE OF SPEECH IN THE THERAPEUTIC PROCESS IN THE \\ DASEINSANALYTIC PHENOMENOLOGICAL APPROACH
}

\author{
Raquel Lessa da Silva JACINTO ${ }^{1}$ \\ Maria Aparecida Magalhães SALLES ${ }^{2}$
}

RESUMO: Este trabalho apresenta a importância da dimensão da fala no processo terapêutico na abordagem fenomenológica daseinsanalítica, compreendendo como constituinte do ser na estrutura ontológica existencial pela qual o Dasein se mostra. Um breve histórico da Daseinsanálise elucida o realizar do homem como humano na linguagem, submetendo a sustentação do processo terapêutico pela fala. Articulada com a linguagem, em que a escuta e o silêncio se fundem na compreensão, procurou-se evidenciar que, por meio da fala original, o Dasein em abertura tem a possibilidade de modificar e transformar seu modo de existir, enquanto a fala secundária põe o homem em fechamento, distanciando-o de escolher seu modo de ser. A metodologia qualitativa e descritiva de coletas de dados no campo bibliográfico, com autores que tratam da temática, corroborou com a compreensão que a fala na psicoterapia é via de trânsito para a modificação e transformação do seu modo de ser e existir.

PALAVRAS-CHAVE: Fala. Falatório. Fenomenologia Daseinsanalítica.

RESUMEN: Este trabajo presenta la importancia de la dimensión del habla en el proceso terapéutico en el enfoque fenomenológico daseinsanalítico, entendiendo como un componente del ser en la estructura ontológica existencial por la que se muestra el Dasein. Una breve historia del daseinsaanálisis aclara la realización del hombre como humano en el lenguaje, sometiendo el sostenimiento del proceso terapéutico por el habla. Articulado con el lenguaje, en el que la escucha y el silencio se funden en la comprensión, buscamos mostrar que, a través del habla original, el Dasein abierto tiene la posibilidad de cambiar y transformar su forma de existir, mientras que el discurso secundario pone al hombre en cierre, distanciándolo de elegir su forma de ser. La metodología cualitativa y descriptiva de la recopilación de datos en el campo bibliográfico, con autores que tratan del tema, corroborado con la comprensión de que el habla en psicoterapia es una vía de tránsito para la modificación y transformación de su forma de ser y existir.

\footnotetext{
${ }^{1}$ Centro Universitário de Barra Mansa (UBM), Barra Mansa - RJ - Brasil. Graduada no curso de Psicologia. ORCID: https://orcid.org/0000-0003-1125-1828. E-mail: raqjacinto2012@gmail.com

${ }^{2}$ Centro Universitário de Barra Mansa (UBM), Barra Mansa - RJ - Brasil. Professora do curso de Psicologia e Coordenadora do Curso de Pós-Graduação em Psicologia. ORCID: https://orcid.org/0000-0001-9373-158X. Email: orientacaocidinha@outlook.com
} 
PALABRAS CLAVE: Habla. Lenguaje. Fenomenología. Daseinsanalítica.

ABSTRACT: This paper presents the importance of the dimension of speech in the therapeutic process in the phenomenological approach of Daseinsanalytic, understanding as constituent of the being in the existential ontological structure through which Dasein shows itself. A brief history of Daseinsanalytic elucidates the realization of man as human in language, submitting the support of the therapeutic process by speech. Articulated with language, in which listening and silence merge in understanding, it has been tried to show that, through original speech, Dasein in opening has the possibility to modify and transform his way of existing, while secondary speech puts man in closing, distancing him from choosing his way of being. The qualitative and descriptive methodology of data collection in the bibliographical field, with authors dealing with the subject, corroborated with the understanding that speech in psychotherapy is a transit route for the modification and transformation of his way of being and existing.

KEYWORDS: Speech. Talk. Daseinsanalytic Phenomenological.

\section{Introdução}

Este trabalho foi desenvolvido para atender a obrigatoriedade da grade curricular do curso de Psicologia do Centro Universitário de Barra Mansa - UBM, como Trabalho de Conclusão de Curso. A escolha do tema 'A importância da fala no processo terapêutico na abordagem Fenomenológica Daseinsanalítica' surgiu durante as aulas da disciplina de Fenomenologia II, conciliadas com as atividades na clínica-escola quando o conteúdo de fala e falatório, apresentado em sala de aula, tomou consistência na experiência clínica.

$\mathrm{O}$ assunto foi 'ganhando força' e, na medida em que se estudava, eram pesquisados artigos a respeito da fala, com citações e escritos do filósofo Heidegger, um dos percussores da fenomenologia.

Este estudo trata-se de uma compilação, não exaustiva, de revisão bibliográfica com intuito de ampliar o conhecimento da dimensão da fala, delinear este campo e seus aspectos ao fazer nuances entre a fala e o falatório, em que se espera compreender não a busca do que originaria dados comportamentais ou modos de ser, mas trazer esclarecimentos do seu sentido.

O estudo desta temática é relevante, pois, os trabalhos que se concentram especificamente no assunto são extensos, enquanto em outros, é citado por pertencer ao âmbito da condição humana. E para se entender que uma articulação entre as experiências na clínica, artigos e conteúdos literários dentro da abordagem fenomenológica daseinsanalítica, o assunto da fala, pode ser compreendida a partir das condições existenciais. 
Procurou-se fazer recortes para montar, de forma sucinta, a importância da fala neste contexto. Conhecer de que forma se dá essa relação com o mundo, quando é dada ao Ser a oportunidade de visitar as possibilidades perdidas, abandonadas, passadas e as futuras. Seria essa possibilidade de articular as experiências, que é dada apenas ao sujeito, ao voltar para o presente, fornecer as ressignificações vivenciais?

Terapia é um pouco isso: possibilidade de dirigir um olhar diferente para a própria existência e, assim, reformular significados. Se na terapia alguém consegue começar a olhar a própria vida e a reelaborar significados que já estavam cristalizados, a realidade da vida dessa pessoa pode se alterar também (SAPIENZA, 2004, p. 26).

Ao proporcionar ao sujeito que ele entre em contato com suas próprias experiências e favorecer que as descreva, o terapeuta alcança os significados vividos pelo sujeito, viabiliza a construção de reflexões que são possíveis caminhos para compreensão de suas próprias experiências e, ao falar de si mesmo, buscar novos modos de compreensão quando provocado ao reviver suas experiências, assim permitir que se apresentem novos modos de ser.

Este trabalho objetiva ampliar a discussão sobre a importância da fala no processo terapêutico na abordagem fenomenológica daseinsanalítica e, ao trilhar este caminho, identificar a dimensão da fala neste processo, compreendendo a abrangência da experiência pessoal no processo terapêutico, por meio da fala.

Tem-se como problemática desvendar como a fala possibilita o homem conhecer-se, sempre a procura de compreender seu modo de ser e de se mostrar, com abertura para que suas experiências ao falar de si mesmo, busque na própria experiência o sentido de sua singularidade e assim possibilite, conforme aponta Morato (2009), uma reflexão e possa alcançar a dimensão do cuidado, o cuidado de si.

A hipótese de que ao percorrer o caminho da compreensão dos fenômenos existenciais propriamente humanos e partir da premissa ser por meio da linguagem, que as histórias são contadas da maneira que melhor condiz com seu modo de ser, de compreender e de ser sentida naquele exato momento. Nesse sentido, Freitas (2017, s/p), ressalta que ela "propicia a possibilidade da pessoa ao compartilhar, ampliar a liberdade com que se envolve, se apropria e participa da história que está incessantemente compondo enquanto existe”.

Para facilitar a compreensão dessa problemática, o texto estará dividido em três partes. Na primeira parte, descrever-se a um pouco sobre a Daseinsanalyse, tida como arcabouço dos fenômenos existenciais propriamente humanos, ao lembrar de que o homem só se realiza como humano na linguagem. Na segunda parte, um pequeno esboço para clarear o 
entendimento sobre o conceito de um processo psicoterapêutico e como ele se dá na clínica daseinsanalítica. Na terceira parte, abranger o campo da fala em sua dimensão, peculiaridades articuladas com a linguagem, exibindo sua essencialidade no existir humano.

\section{Desenvolvimento}

Este trabalho caracteriza-se como um estudo qualitativo e descritivo, conforme proposta de autores da área científica. Para os procedimentos de coleta de dados, classifica-se como pesquisa bibliográfica de literaturas fenomenológicas, existencial e daseinsanalítica, compostas por artigos variados considerando o mesmo eixo comum da temática, conteúdos que pudessem embasar esse trabalho de forma possibilitar uma reflexão da prática clínica na abordagem fenomenológica daseinsanalítica.

Optou-se por essa metodologia pela importância dos estudos, a partir das experiências relatadas, o caminho que se tomou para o desvelamento da singularidade e no pluralismo de conteúdos que há na comunicação mais própria do ser humano, a de contar suas próprias histórias, de compartilhar, criar e recriar acontecimentos.

De acordo com Dutra (2002), quando o homem conta suas experiências, ele exercita sua compreensibilidade, trazendo consigo o que lhe é constituinte em sua condição estar-nomundo, seu modo de ser no mundo, articulado através da linguagem e da compreensão.

\section{A Fenomenologia Daseinsanalítica}

Para contextualizar a prática fenomenológica daseinsanalítica, faz-se necessário olhar para uma breve linha histórica. Conforme Freitas (2017, s/p) foi no encontro de Merdad Boss com os escritos de 'Ser e Tempo' de Heidegger que se deu a compreensão do homem como Dasein, dando o ponto de partida, a clínica psicoterápica designada de Daseinsanálise. Um termo alemão que significa literalmente, ser-aí, que designa o modo de ser do Dasein, Dasein é uma expressão cotidiana alemã que significa existência. Heidegger utiliza esse termo para designar o ser do homem, a tradução mais aproximada em português é "Ser-á́" e traz a compreensão existencial. 
Na mesma compreensão, Da Costa $(2017$, p. 178) diz que "o termo foi usado com o intuito de designar a explicitação filosófica dos existenciais, ou seja, das características ontológicas $^{3}$ constituintes do existir humano".

Composta por duas palavras, o termo Daseinsanalyse, considera fundamentalmente o problema do ser, usando o 'Dasein' para designar o ente humano e 'análise' direcionada ao "processo de libertação das algemas ou o tecer e destecer de uma trama" (DA COSTA, 2017, p. 178).

Conforme De Oliveira (2008) foi a partir de uma crítica às metapsicologias e para contrapor às formas de pensar em que os fenômenos eram reduzidos às questões de causa e efeito, que o fazer dessa modalidade procura acesso aos fenômenos que se desvela, que se mostra, tal como é, afastando-se de psicologismo, ao considerar uma postura, diferenciada e nova do analista em relação ao seu analisando.

É atribuída a Binswanger e posteriormente a Boss (apud PEDGEN; FERREIRA, 2015) a utilização do termo daseinsanalyse clínica, ou daseinsanálise, porém com vieses diferentes. Faz-se menção a Boss como contribuidor importante para o desenvolvimento da Daseinsanalyse primeiro pela aliança de amizade e trocas sobre Filosofia e Daseinsanalyse com Heidegger, dando origem a obra Seminários de Zollikon, compilação de eventos de 1959 e 1969, em que Heidegger retoma o pensamento sobre essa prática, segundo junto com Gion Condrau fundou a Sociedade de Daseinsanalyse Suíça em 1970, Pedgen e Ferreira (2015) em terceiro a participação junto com Solon Spanoudis, a consolidação da Daseinsanalyse no Brasil, na década de 1970, conforme Da Costa (2017).

Conforme Freitas (2017), ao utilizar o método fenomenológico, o intuito é de ajudar a compreender como o dasein experimenta seu-mundo, abrir espaço para recontar sua história e se colocar como protagonista dela, identificar suas escolhas, promover a abertura em relação a si e mobilizar suas capacidades e potencialidades exercendo plena liberdade de entoar a própria voz.

A Daseinsanálise viabiliza à pessoa retomar seu próprio existir, suas infinitas possibilidades, devolvendo-lhe a tarefa do cuidado da própria existência, ao transitar na temporalidade da sua própria história, afirma Da Costa (2017).

Esse transitar é viabilizado pela linguagem, nessa via, a Daseinsanálise considera a linguagem não como ferramenta de uso e controle, mas sim “é ela própria que nos possui

\footnotetext{
${ }^{3}$ Diz respeito aos Existenciais, condições compartilhadas entre todos os homens (DE OLIVEIRA, 2008, p. 14); modo de ser do homem diferenciando do ôntico que trata dos "interesses cotidianos, individualidades, cultura, grupos - brasileiros, psicólogos, escritores” (ROEHE; DUTRA, 2014, p. 107).
} 
enquanto se oferece como morada" (FREITAS, 2017, p. 7). Dessa forma, é a responsável por articular o mundo, coisas, pessoas, espaços e de situar todos em fatos históricos passados, como também em projetos do futuro no campo das possibilidades e nisso, também, torna-se um instrumental que entremeia o estar-aberto humano, o poder-ouvir, poder-responder e poder-corresponder. Conforme expõe Dutra (2002, p. 375):

A linguagem ocupa um lugar central na filosofia heideggeriana, sendo considerada a morada do ser, e é nela, na linguagem, que o ser se desvela. É ainda a linguagem aquela que assume a condução na direção da elaboração do método e da analítica existencial.

Freitas (2017, p. 5) afirma que, "lembrar que o existir humano se realiza como humano na linguagem, a partir de sua incompletude, a partir de sua liberdade para ela. Cada qual a partir de seu modo mais eloquente de linguagem". A linguagem é um fundamento ontológico-existencial que constitui a abertura do Dasein, ao utilizar o discurso para articular, na unidade da temporalidade do Dasein, passado, presente e futuro.

\section{Processo terapêutico}

“Terapia é pró-cura", isto é, "terapia é para cuidar"; o significado de cura no latim, é cuidar de acordo com Sodelli (2012). Assim, processo terapêutico deve ser compreendido como o 'ato de curar' ou de restabelecimento, na clínica fenomenológica daseinsanalítica, o conceito de cuidado e o principal caminho para esse cuidado é através da hermenêutica, como afirma De Oliveira (2008).

Conforme De Oliveira (2008), comumente, um paciente que se vê vítima de um erro, trauma ou um mal em si, solicita ao terapeuta uma solução para seu problema, ele perde a visão de que este problema ou dificuldade pode ser uma oportunidade de crescimento. Põe em jogo a sua liberdade, quando solicita isenção dela pedindo a solução do seu problema.

Não é foco da Daseinsanálise a cura, mas o tratar, atender aos desdobramentos da palavra cura que leva ao exercício do cuidado, entendido como uma das estruturas existenciais (pertencentes ao Dasein) pode-se dizer que cabe ao terapeuta o devolver ao outro o cuidado de ser, ajudando-o a assumir o Homem, Resoluto, conduzido no processo terapêutico alçar sua finalidade, em clarear o caminho da libertação.

A Daseinsanályse como forma de aproximação ao Dasein, no âmbito da psicoterapia, tem particularidades especialmente por não ser uma teoria na concepção que usualmente se emprega. É um método, é um caminho em direção ao ser, em direção ao desvelamento do ser. Esta aproximação leva 
em conta o ocultar e desvelar do ser, com o intuito de se chegar à compreensão do sentido do caminhar deste ser que é o analisando, ou paciente (DE OLIVEIRA, 2008, p. 14).

Nesses termos, o processo terapêutico, também tratado como psicoterapia, não está destinado a intervir curando o indivíduo, mas contribuir para seu crescimento e transformação, aproximando-o da autenticidade do seu modo de ser.

Face ao indivíduo que busca ajuda, os modelos pré-concebidos de enquadramento do ser humano, podem abrandar o estado apreensivo e temeroso do terapeuta, o que o leva a um distanciamento dos fenômenos que se apresentam em cada momento.

Para De Oliveira (2008), o daseinsanálise traz a instigação para que o analista se aproprie do seu lugar testemunhando a fala do outro, que se atenta para o sentido, dando pistas a respeito do ser que está em pauta,

O processo terapêutico, na clínica daseinsanalítica, considera uma precisão minuciosa das descrições dada pelo analisando. O analista, em busca de alcançar uma compreensão do que se apresenta nestas descrições, atenta para as interpretações do analisando, afasta comportamentos ontológicos que se deixem mostrar e permite abertura para que o outro se aproprie em sua alteridade.

Conforme Feijoo (2011), abre caminho, sem induzir; traduzir, sem indicar um caminho que leve a algo como uma conscientização, permite que ele apareça a si mesmo.

Então, qualquer cuidado terapêutico tem a ver com o devolver, recuperar ou resgatar para aquilo que é cuidado, algo que diz respeito a ele e que por algum motivo foi perdido ou prejudicado; isso quer dizer: favorecer que aquilo que se cuida retorne mais plenamente àquilo que se espera dele, ao que é próprio dele. Visto que aquilo que se cuida na terapia é o fenômeno existência, e permitir que esse fenômeno se revele, compreende-lo, explicitar essa compreensão numa linguagem é [...] terapêutico [...] (SAPIENZA, 2004, p. 56).

A linguagem ocupa um lugar central nesse processo, ao permitir que o fenômeno que se revelou se mostre por inteiro possa ser compreendido. Nesse encontro, o homem pode apropriar-se do que é seu, pode dar sentido para sua existência, destituir-se de suas amarras, ressignificar sua situação no mundo.

Freitas (2017) contribui com esse raciocínio ao evidenciar que neste processo de falar, enquanto os fatos aparecem, o homem se posiciona neste enredo, no exercício pleno da liberdade, entoa a própria voz, possibilita o encontro com os fenômenos de seu existir, junto à postura de ouvinte atento do terapeuta daseinsanalista que busca compreender o sentido desse enredo e possa devolver à história deste Dasein, seu sentido singular. 
Vê-se então neste processo da clínica daseinsanalítica, conforme (FREITAS, 2017, p. 10) o "[...] pôr-se-em-obra na obra feita de linguagem que é tecida em conjunto na terapia". É nisso que consiste a busca na clínica, diz Pereira et al. (2007, s/p), "abertura do sujeito para regiões de si, permissão para adentrar em seu ser e resgatar uma fala geradora de novas possibilidades, sempre à procura de compreender seu modo de ser e de mostrar".

\section{Dimensão da fala}

A filosofia heideggeriana conceitua a linguagem como ponto central do existir humano, considerada como a morada do Ser e é nela que o Ser se desvela.

Para fazer uma compreensão entre fala e linguagem, recorrer-se-á a Almeida (2005, p. 201) ao parafrasear Heidegger, mostra que a função da fala é “[...] desocultar tudo o que é próprio do ser-no-mundo" e que ela é originária do existir humano tanto quanto, o sentir e compreender, para dar-lhe sentido se articula com a interpretação trazida pela linguagem.

Nesse sentido, a linguagem é a via de representação da realidade, não reduzida a um objeto, mas sendo sustentada por uma rede de significados, mostra o fenômeno tal qual ele é. “O homem fala à medida que corresponde à linguagem" afirma Heidegger (2003, p. 26).

Conforme Almeida (2005, p. 203), “A fala comunica sentidos e a linguagem, expressão da fala, articula significados, possibilitando que os falantes se tornem comuns"

Segundo uma antiga tradição, nós somos aqueles seres capazes de falar e, assim, aqueles que já possuem a linguagem. A capacidade de falar, ademais, não é apenas uma faculdade humana, dentre muitas outras. A capacidade de falar distingue e marca o homem como homem. Essa insígnia contém o desígnio de sua essência. O ser humano não seria humano se lhe fosse recusado falar incessantemente e por toda parte, variadamente e a cada vez, no modo de um 'isso é', na maior parte das vezes, impronunciado. À medida que a linguagem concede esse sustento, a essência do homem repousa na linguagem. Somos, antes de tudo, na linguagem e pela linguagem (HEIDEGGER, 2003, p. 191).

É comum pensar na linguagem como veículo de expressão que vincula o que está dentro com o que está fora do homem, da mesma forma que a fala é pensada numa atividade que acontece por meio do homem.

Torna-se necessário delinear os aspectos ontológicos existenciais e ressaltar que não é o homem quem 'tem' a linguagem por ter a capacidade de falar, mas é a linguagem que desvela o modo no qual se manifesta o homem 'sendo'. Para além de uma mera função comunicativa, a fala pode tornar-se íntima, proporcionar um espaço de abertura à dimensão 
existencial do homem, sendo este autor e protagonista de sua própria história e delimitar assim, a liberdade que esse tem em assumir à própria existência.

Assim sendo, Roehe e Dutra (2014, s/p) contribuem ao ressaltar que "[...] a fala como característica constitutiva do Dasein [...] não é a expressão verbal como costumeiramente se entende, esta é a linguagem [...]; é mais ampla, dela fazem parte a escuta e o silêncio”.

O 'poder-escutar' é possibilitado pelo silêncio, quando o Dasein em sua abertura própria, tem algo a dizer. "Fala e escuta se fundem na compreensão" afirma Heidegger (2005, p. 223-224).

Nessa travessia pela dimensão da fala, ao se atentar não somente ao conteúdo, como também à forma do que é feito e dito, não se está em busca do que originaria dados comportamentais ou modos de ser, mas trazer esclarecimentos do seu sentido. Conhecer de que forma se dá sua relação com o mundo e possibilitar visitações às possibilidades perdidas, abandonadas, às futuras, presentes e passadas.

É na dimensão da fala que se dá essa possibilidade, que faz o elo, a sustentação para que esse trânsito ocorra, ao voltar ao real, fornece significações conclui Morato (2009).

Segundo Sapienza (2004), o falar é muito mais do que comunicação e diferencia outras espécies que utilizam deste mecanismo para mostrar o que existe, o homem usa a fala para mostrar aquilo que não existe. Ele pode unir passado, presente e futuro estampar realidades e possibilidades.

Da Costa (2017), salienta a daseinsanalyse fundamentada em bases heideggerianas e afirma que a psicoterapia acontece via 'poiesis', ou seja, via um trazer à luz aquilo que se apresenta. $\mathrm{O}$ autor, ao propor o caminho da psicoterapia via linguagem poética, coloca a compreensão em evidência, uma vez que nessa via de linguagem o interlocutor, ou terapeuta, é tocado pela fala do analisando de uma forma distinta da explicação racional.

Em seguida, para expressar aquilo que se manifesta na fala, via linguagem poética, o autor introduz a noção de 'aletheia' ${ }^{4}$ como explicitada por Heidegger (apud DA COSTA, 2017), ou seja, aquilo que se mostra desvelado.

Para Pereira et al. (2007) o homem em busca de compreender a si mesmo, depara-se com suas dores as quais trazem comprometimento ao sentido de sua vida e, preso neste emaranhado de emoções e na impossibilidade de pronunciar palavras, vive um conflito difícil de ser compartilhado. Um sofrimento que o priva de sua linguagem, não se enxergando como criador e gerador de sentido.

${ }^{4}$ Aletheia (grego; aleteia transl.) compreendida por Heidegger "aquilo que se mostra desvelado" (DA COSTA, 2017, s/p). 
É importante ressaltar neste ponto, a importância da fala no processo terapêutico, em que o terapeuta daseinsanalista deve, segundo De Oliveira (2008) se atentar ao que se oculta e se desoculta, compreender o modo de ser do Dasein, ajudando-o a se apropriar do sentido a sua própria história.

Nessa via, Roehe e Dutra (2014, p. 111) ressaltam que o apropriar-se de si mesmo, faz jus ao responsabilizar pelas escolhas que faz, quando se assume "[...]a liberdade de escolher a própria responsabilidade de fazer escolhas".

Utiliza-se Freitas (2017, s/p) para clarificar essa ideia, de buscar "via linguagem da poiesis pela verdade que liberta. Verdade que se liberta na clareira envolta em escuridão e poder ser vista. Verdade que liberta o paciente para se dedicar ao sentido próprio do seu existir", vê se na clínica um espaço de vivenciar a experiência da linguagem, num movimento de transformação, potencializar essa luta para se descobrir um modo singular de existir.

Para experienciar essa fala criadora, que transforma e mobiliza, o indivíduo precisa ser transparente e dar-se de si mesmo na fala original que se diferencia da fala secundária, em que o discurso pronto está "recheado de pré-conceitos e ignorância dos próprios sentimentos e pensamentos" (MORATO, 2009, s/p).

Esse discurso pronto afirma Pereira et al. (2011), que o leva a se isentar da responsabilidade por si mesmo, pode-se denominar por fala impessoal, nada pode acrescentar de verdadeiro e ainda impossibilita a compreensão de sua condição existencial autêntica.

\footnotetext{
Neste viés contemplamos a possibilidade da fala feita de maneira distanciada, como relato de uma experiência ou história, de forma impessoal, referenciada na Queda heideggeriana, podendo mostrar uma fuga ou tentativa desta, de si mesmo. "A questão aqui é falar, sem necessariamente haver preocupação com a veracidade deu um ponto de referência, pois o que faz sentido é repetir e passar adiante a fala" (HEIDEGGER, 2005, p. 228 apud MORATO, 2009).
}

Essa fala inautêntica é mostrada pelo falatório que, segundo Heidegger (apud MORATO, 2009, p. 229), "transforma a abertura em fechadura, por abster de retornar à base e ao fundamento referencial, propõe reprimir, postergar e retardar toda e qualquer questão e discussão", que tira do ser homem a possibilidade de, ao compartilhar, ampliar a liberdade, apropriar e participar da sua própria história enquanto a compõe.

É necessário retirar o falatório e permitir que a compreensão seja restaurada em sua singularidade, se permitindo ao desenclausuramento colocar-se em "trânsito da abertura de si mesmo, para o mundo e para os outros", de acordo com Morato (2009, s/p). A conquista da liberdade, a partir da libertação de si. 
Segundo Augras (1986, p. 80) "a fala torna possível o mundo”, o homem, para apropriar-se da sua própria humanidade, é indispensável se reconhecer como criador e protagonista de sua história, assumindo a responsabilidade por si mesmo na construção de possibilidades de sentidos concomitantemente sendo marcado por suas experiências.

\section{Considerações finais}

O desenvolvimento deste estudo possibilitou ampliar a discussão sobre a importância da fala na clínica daseinsanalítica pelo método fenomenológico. O espaço terapêutico é marcado, também, por muito falatório em seu discurso impessoal, fala destituída de responsabilidade, em que a compreensão é feita de qualquer forma e jeito. Consequentemente, de certa impropriedade, que indica um modo de ser, sem direção, perdido de si próprio, percebidos nos estágios de clínica (MORATTO, 2009). Além disso, a metodologia adotada permitiu traçar na estrutura ontológica-existencial do Dasein a dimensão da fala no contexto psicoterapêutico.

Entendeu-se sua relevância quando em busca de artigos, livros, conteúdos dentro da temática como articuladores da experiência da clínica, por ser constituinte das condições existenciais, eram amplos, extensos enquanto alguns com trechos e breves citações, fundamentava a fala dentro de uma estrutura ampla da condição humana o que possibilitou que se trilhasse neste campo em busca de compreender sua atividade em clínica e pudesse clarificar seu manejo.

Para alcançar uma compreensão da importância da fala nesse contexto, definiram-se dois objetivos específicos, sendo o primeiro para identificar a dimensão da fala e iniciou-se ao fazer distinção entre fala e linguagem, em que fala refere-se a sentidos e a linguagem, expressão da fala, articula significados.

Buscou-se transcorrer os seus correlatos, escuta e silêncio, como aspectos constitutivos que se fundem na compreensão. O Dasein se projeta, se antecede ao futuro, na situação que ele vem sendo no passado, para lidar com o que vem ao seu encontro no presente, conforme Roehe e Dutra (2014).

O segundo objetivo específico tratou de compreender a abrangência da experiência pessoal no processo terapêutico por meio da fala.

Evidenciou-se que, independente da orientação teórica que esteja embasada, a fala é fundamental na prática clínica, pressupondo que a abordagem fenomenológica 
daseinsanalítica não está implicada numa perspectiva do modelo científico das ciências naturais e do senso comum.

Essa abordagem procura conhecer o homem em seu modo de ser, como se dá sua relação com o mundo, e com os outros, é no falar de si que o homem se abre para ter acesso à sua singularidade e assim poder voltar à sua vivência e resgatar sua autenticidade e permitir que se apresentem outros modos de ser.

O homem moderno que é marcado por muitas experiências, lutas, sofrimentos, ausência, presença, conquistas, perdas se apresenta à clínica, instigado a construir ou reconstruir sua história quando esta é contada. Por isso, a fala tem a função libertadora por provocar mudanças no modo de existir.

Considera-se, a partir dessas leituras que a hipótese traçada inicialmente para esse projeto de caminhar através da compreensão dos fenômenos existenciais do campo da fala, possibilita o homem resgatar sua originalidade expressando seu modo de ser e estar-nomundo e com os outros.

Por tratar de uma terapia essencialmente verbal, a fala levaria o Dasein (ser-aí) a abertura de regiões de si mesmo e a partir daí se conectar aos fenômenos existenciais e, neste contexto, não se atentar apenas ao conteúdo daquilo que é dito, como também para a forma e o modo como a pessoa o faz, percorre pelo caminho da compreensão dos fenômenos existenciais propriamente humanos.

A partir da premissa, é através da linguagem que as histórias são contadas da maneira que melhor condiz com seu modo de ser, de compreender e de ser sentida naquele exato momento; é a fala que propicia a possibilidade da pessoa ao compartilhar, segundo Freitas (2017, p. 2), "ampliar a liberdade com que se envolve, se apropria e participa da história que está incessantemente compondo enquanto existe".

Ao descortinar as possibilidades, o homem é projetado ao dar-se à possibilidade de ser puxado do interior da realidade. É neste movimento que ele se depara com todas as possibilidades: as perdidas, abandonadas, as que nem foram consideradas, as passadas, as do presente e as futuras. E essa visitação só ocorre por meio da fala, fundamentando e fornecendo o chão para que esse trânsito ocorra e possa trazer as significações quando ele volta ao real (DE OLIVEIRA, 2008).

A psicoterapia, além de ser um espaço de mudança e transformação- articulada pela fala que define e provoca mudanças no modo de existir- caminha junto ao analisando para uma fala criadora e produtora de sentidos, busca organizar, estruturar e observar o rumo da 
narrativa. a ponte que leva a investigar a situação do ser no mundo, no encontro com o outro e a si mesmo é a compreensão da fala (AUGRAS, 1986).

Devido a importância do assunto, este trabalho não pretendeu esgotar a questão da fala, mas de clarificar sua importância no processo terapêutico na abordagem fenomenológica daseinsanalítica para auxiliar nas pesquisas iniciais da prática clínica, fundamentado no conceito que o homem só se realiza pela linguagem.

\section{REFERÊNCIAS}

ALMEIDA, F. M. Ser clínico como educador: uma leitura fenomenológica existencial de algumas temáticas na prática de profisssionais de saúde e educação. 2005. 215 f. Tese (Doutorado em Psicologia) - Universidade de São Paulo. Disponível em: https://www.teses.usp.br/teses/disponiveis/47/47131/tde-08082007180214/publico/tese_de_fernando_almeida.pdf. Acesso em: 27 set. 2019.

AUGRAS, M. O ser da compreensão. 3. ed. Petrópolis: Vozes, 1986.

DA COSTA, B. A. Daseinsanalyse e psicoterapia no Brasil: uma revisão integrativa da literatura. Revista da Abordagem Gestáltica: Phenomenological Studies, v. 23, n. 2, p. 177-188, 2017. Disponível em: https://www.redalyc.org/pdf/3577/357752154006.pdf. Acesso em: 24 ago. 2019.

DE OLIVEIRA, L. M. A prática clínica daseinsanalítica: especificidades. 2008. Monografia (Trabalho de Conclusão de Curso de Psicologia) - Pontifícia Universidade Católica, São Paulo, 2008. Disponível em:

https://sapientia.pucsp.br/bitstream/handle/18639/2/Liliana\%20Martins\%20de\%20Oliveira.pd f. Acesso em: 24 ago. 2019.

DUTRA, E. A narrativa como uma técnica de pesquisa fenomenológica. Estudos de psicologia, v. 7, n. 2, p. 371-378, 2002. Disponível em:

http://www.scielo.br/pdf/\%0D/epsic/v7n2/a18v07n2.pdf. Acesso em: 28 ago. 2019.

FEIJOO, A. M. L. C. A clínica daseinsanalítica: considerações preliminares. Rev. abordagem gestalt, Goiânia, v. 17, n. 1, p. 30-36, jun. 2011. Disponível em http://pepsic.bvsalud.org/scielo.php?script=sci_arttext\&pid=S180968672011000100006\&lng=pt\&nrm=iso. Acesso em: 21 nov. 2018.

FREITAS, D. P. A caminho da linguagem na experiência da daseinsanalyse clínica. Rev. Associação Brasileira de Daseinsanalyse, São Paulo, n. 17, 2017. Disponível em http://www.daseinsanalyse.org/artigo.php?id=5. Acesso em: 04 ago. 2018.

HEIDEGGER, M. A caminho da linguagem. São Francisco: Ed. Universitária, 2003.

MORATO, H. T. P. et al. Aconselhamento psicológico numa perspectiva fenomenológica existencial: fundamentos de psicologia. Cap. VXIII. Grupo Gen-Guanabara Koogan, 2009. p. 255-269. 
PEGDEN, R. T. F. M.; FERREIRA, A. A. L. Com quantas redes se escreve uma história da daseinsanalyse? Summa Psicológica UST, v. 12, n. 1, p. 17-26, 2015. Disponível em https://dialnet.unirioja.es/servlet/articulo?codigo=5147361. Acesso em: 05 nov. 2018.

PEREIRA, L. F. F. et al. Da experiência da fala de sujeitos usuários na clínica psicológica às suas possíveis repercussões. Psicol. cienc. prof., Brasília, v. 27, n. 3, p. 476-495, set. 2007. Disponível em: http://pepsic.bvsalud.org/scielo.php?script=sci_arttext\&pid=S141498932007000300009\&lng=pt\&nrm=iso. Acesso em: 27 set. 2019.

ROEHE, M. V.; DUTRA, E. Dasein, o entendimento de Heidegger sobre o modo de ser humano. Avances en Psicología Latinoamericana, v. 32, n. 1, p. 105-113, 2014.

SAPIENZA, B. T. Conversa sobre terapia. São Paulo: Educ. Paulus. 2004

SODELLI, M.; SODELLI-TEODORO, A. Visitando os "seminários de Zollikon": novos fundamentos para a psicoterapia fenomenológica. Psicologia Revista, [S.1.], v. 20, n. 2, p. 245-272, set. 2012. ISSN 2594-3871. Disponível em:

https://revistas.pucsp.br/psicorevista/article/view/10343. Acesso em: 28 ago. 2019.

\section{Como referenciar este artigo}

JACINTO, R. L. da S.; SALLES, M. A. M. A importância da fala no processo terapêutico na abordagem fenomenológica daseinsanalítica. Doxa: Rev. Bras. Psico. e Educ., Araraquara, v. 22, n. esp. 1, p. 315-328, out., 2020. e-ISSN: 2594-8385. DOI: https://doi.org/10.30715/doxa.v22iesp.1.14136

Submetido em: 20/04/2020

Revisões requeridas: $15 / 06 / 2020$

Aprovado em: 20/08/2020

Publicado em: 30/09/2020 